\title{
ORIGINAL ARTICLE \\ Noteworthy predation on bats by the Common Genet (Genetta genetta) in southern France
}

\author{
Christian Riols ${ }^{1, *}$, Renaud Nadal ${ }^{2}$
}

\author{
${ }^{1}$ Ligue pour la Protection des \\ Oiseaux de l'Aude, Écluse de \\ Mandirac, 11100 Narbonne, \\ France. \\ ${ }^{2}$ LPO Lot, Espace Clément Marot, \\ Place Bessières, 46000 Cahors, \\ France. \\ *Corresponding author e-mail: \\ christian.riols-loyrette@orange.fr \\ DOI: https://doi.org/10.14709/ \\ BarbJ.11.1.2018.07 \\ Keywords: bats, genet, \\ predation, southwestern France, \\ swarming, specific context.
}

received: April, 11th 2018 accepted: August, 21st 2018

\begin{abstract}
According to current literature, bats are barely found in Common Genet diet and their interaction poorly known. Successive collections of genet scats from 2013 to 2016 on a rocky site in Quercy (Lot, southwestern France) revealed outstanding predation on a band of bats, mainly Myotis (7 species). No fewer than 173 bats of nine species have been taken over four years: the more common species were Bechstein's, Natterer's and Daubenton's Bats. This predation, which is without any known precedent in France or Europe with the possible exception of a Portuguese site, suggests the use of our sampling site as a swarming place for bats. Its specific settings and characteristics are the more reliable explanation for this phenomenon, local specialization which has probably existed for a long time. Almost all bats were taken in September-November. This and the presence of many juvenile bats ( $35 \%$ ) would indicate that this predation is probably related to the bat's swarming activity.
\end{abstract}

\section{INTRODUCTION}

Numerous dietary studies confirm bat predation by birds in Europe, mainly raptors and more especially owls (Lesinski et al. 2012, Lima \& O'Keefe 2013, Roulin \& Christe 2013). However, there are very few data concerning predation by wild carnivorous mammals. For instance, the Badger (Meles meles) was once reported as predator of a Greater Mouseeared Bat (Myotis myotis) by Bertrand (1992). The Stone Marten (Martes foina) and Pine Marten (Martes martes) are more liable to prey on bats but are barely mentioned in the literature; the former as an occasional predator of Daubenton's Bat (Myotis daubentonii in the Netherlands (Bekker 1988) and other bats in Romania (Romanowski \& Lesinski 1991). The latter mentioned a supposed incident of predation on Lesser Horseshoe Bat (Rhinolophus hipposideros) in Ireland and an insignificant occurrence of predation frequency $<0.5 \%$ in the Bialowieza Forest in Poland (Jedrzejewska \& Jedrzejewski 1959). Both of these mustelids are reported as feeding on bat carcasses but also as being active predators on non-explicit species in the huge wintering Polish site of Nietoperek (Schofield 2012). Extensive studies of medium-sized mammals' diet were undertaken in northeastern France (Champagne) analysing a total of 20,736 Martes martes and 15,215 Martes foina scats (Riols in prep). Amongst 11,292 mammals predated by the Pine Marten only three bats were detected (one Nyctalus noctula and two small unidentified specimens), whereas amongst 15,856 mammals prey individuals recorded for Stone Marten only six bat specimens were found (one Eptesicus serotinus, two Pipistrellus pipistrellus and three small unidentified bats). In the same study, the Wildcat (Felis silvestris) did not appear as a potential predator since no bats were listed amongst 7,694 preys detected in Champagne (Riols in prep).

Despite some anecdotal mentions in the literature, the role of the Common Genet, medium-sized generalist carnivore, as a bat predator remains quite unknown. Numerous diet studies have been carried out throughout the Common Genet's range in the Western Mediterranean periphery (North Africa, Iberian Peninsula, France), but only a few of them report bat captures (Mas et al. 2015). The authors also reviewed occurrences of bats in the genet's diet, mainly reporting several Schreibers' Bats (Miniopterus schreibersii) found partially eaten in the caves of southern Portugal (Palmeirim \& Rodrigues 1991) and some isolated reports from Catalonia (northeastern Spain): one Schreibers' Bat captured in a mist-net during a cave survey, one undetermined Myotis and three unidentified bats found in faeces (Arrizabalaga \& Montagud 1984, Mas et al. 2015). In France, before the current work, only one bat was listed in the Common Genet's diet, in the Lot department (Nadal \& Riols 2011).

In France, the Common Genet is a non-native introduced species that is now widely dispersed in the southern half of country, still limited in number throughout the North near the Loire valley. However, over several decades, it has largely extended its perimeter beyond the Rhône valley, where the natural habitats remain fairly circum-Mediterranean. A good number of the expansion areas for this species have large 
rocky cliffs: the valleys are frequently deep with cutting limestone plateaus, and low granite or volcanic mountains. Thus, due to the environmental characteristics and the calcareous surroundings, numerous bat colonies (maternity, transit, hibernation) can be found in the region. Because of the abundance of bat colonies, their presence throughout the year, and their co-occurrence with genets, interactions between genets and bats are highly conceivable but rarely reported in the literature. Due to this lack of knowledge, a project aiming at describing genet's diet on the frontier of its distributional range throughout France started in 2007.

\section{MATERIAL AND METHODS}

\section{Study area}

The municipality of Crégols lies on left bank of the river Lot, at the edge of Limogne limestone plateau. At an elevation of $200-400 \mathrm{~m}$, this plateau includes large woodlands with mainly Downy Oak Quercus pubescens and Montpellier Maple Acer monspessulanum. Moorlands with Box Buxus sempervirens and Juniper Juniperus communis are predominating in open areas on calcareous soils. Climate, under oceanic influence, is temperate and fairly warm. Relatively significant rains occur throughout the year but the chalky nature of the soil explains the Mediterranean character of vegetation. Mean temperature is $10.4^{\circ} \mathrm{C}$, with very warm summers, and annual sunshine of 2000-2250 hours. Slopes of the plateau (rivers Lot, Célé and Dordogne) shelter plentiful populations of species related to rocky habitats (Peregrine Falcon Falco peregrinus, Eagle Owl Bubo bubo, Alpine Swift Apus melba, Crag Martin Ptyonoprogne rupestris, Mediterranean horseshoe Bat Rhinolophus euryale, Geater horseshoe Bat $R$. ferrumequinum) etc.

\section{Scat collection}

As part of the French study, 12,050 scats from 24 departments (units of local government) (Fig. 1) have been analyzed so far, with unequal volume depending on supply, with very comprehensive data for 15 departments (> 500 preys, listed in Table 2). One of these places is the Lot department with the outstanding amount of 1,975 scats analyzed, 10,620 food items and 9,082 prey individuals found. Here, since 2007, the specific project allowed us to collect droppings in latrines found at the top or bottom of cliffs, or even in small caves inside, from some valleys in the southern part of Lot (Quercy) (Nadal \& Riols 2011). Here we report an occurrence of predation on bats by the Common Genet in France which has not been reported previously in Europe.

On 26/12/2013, 220 genet scats were collected at a dropping place on a new site at Crégols (Lot) (Fig. 1 \& 2). In order to obtain a better understanding of its diet at the border of the distributional range of the genet, we decided to continue collecting scats on this site at the end of each of the three following years. Further collections were made on $27 / 12 / 2014,28 / 12 / 2015$ and 28/12/2016. The droppings were collected at the bottom of an igue shallow hole, $1 \mathrm{~km}$ from the Lot valley. This igue, about $20-30 \mathrm{~m}$ deep and 70 $\mathrm{m}$ large, resulting from the collapse of the roof of a a cave, faces south and is visited by bats often during the swarming season.

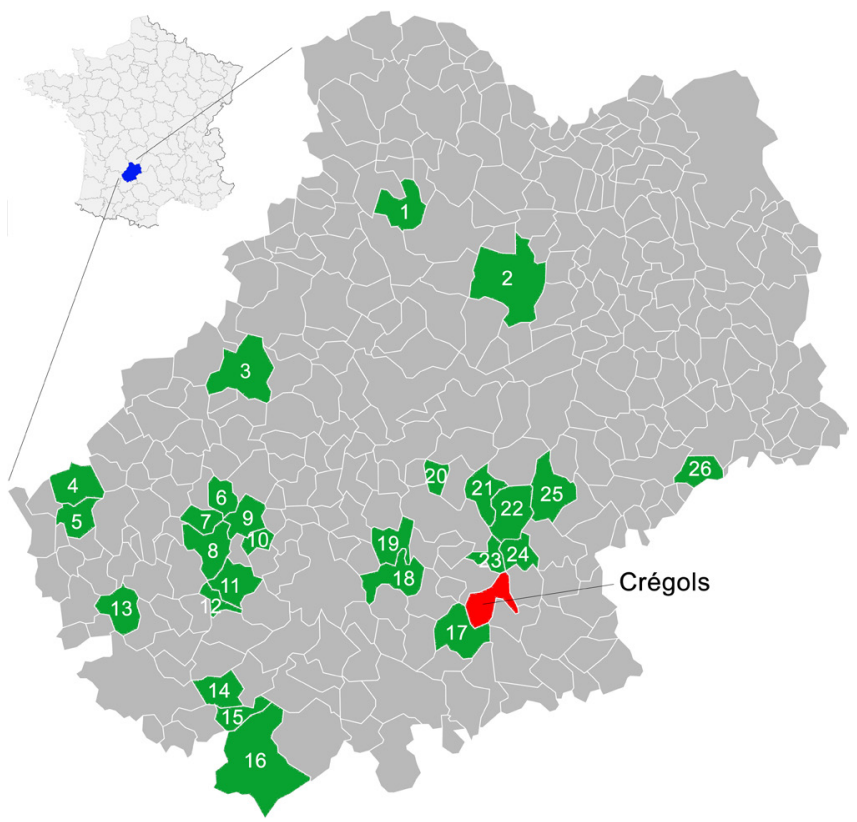

Fig. 1 - Lot department with different collection sites (green) and the sampling site in Crégols (red). Map has been modified from Poulpy's file available in Wikimedia commons (Coordinates are taken from GEOFLA ${ }^{\circledR}$ Communes, a work of Institut Géographique National, licensed under the Licence Ouverte).

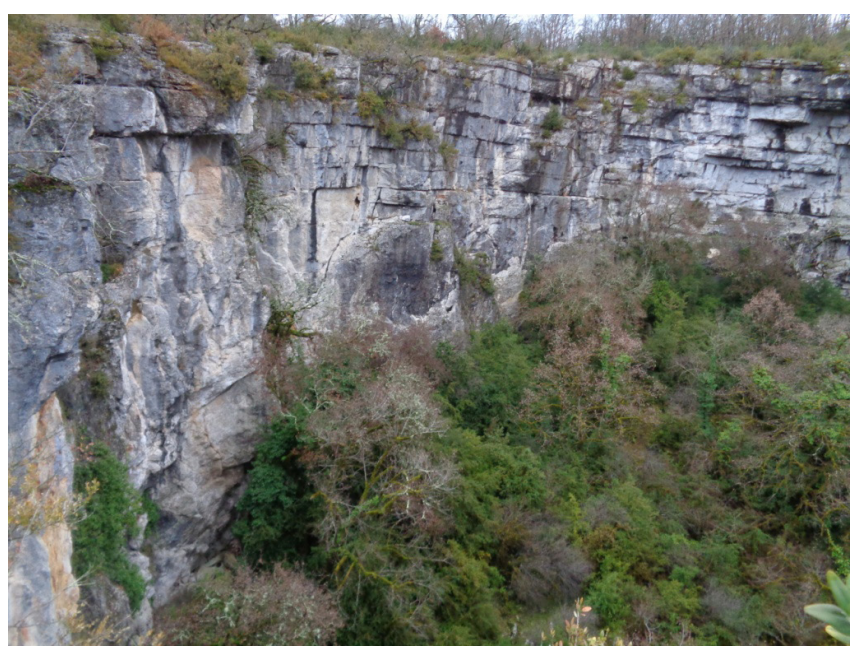

Fig. 2 - Crégols igue and its vegetation.

\section{Scat analysis}

Genet scats were dried after collection and then dissected thinly in order to pick up all components that are required for identification of remains: bones, teeth, feathers, hairs, chitinous fragments, seeds, etc. Prey items were identified to species level whenever possible, using our own reference collection (C. Riols, unpublished). Since bat remains (skulls, long bones) are fairly obvious in scats, they were pulled out easily: they could be identified by their cranial structure and after inspection of teeth rows, using our own reference collection and published identification keys (Britton-Mella 1982, Menu \& Popelard 1987). Identification of bat remains between 2014 and 2016 was carried out by J-J. Chaut using the collection from the Museum of Natural History of Bourges. 


\section{RESULTS}

From the first collection in 2013, no fewer than 1,130 food items (minimum number of individuals of each species found on the total scat batch), including 981 prey, were identified. A total of 20 mammal species were found among 498 individuals and at least 12 bird species ( 22 individuals), two eggs, three reptile species (4), one fish, 20 insect species (141) and four other various invertebrates (spiders, myriapods, gastropods an earthworms). However, small rodents (especially the Wood Mouse, Apodemus sylvaticus) represented $75 \%$ of the total prey numbers. This batch of scats, however, contained the remains of 91 bats (Table 1). More than $80 \%$ of them could be identified: one Leisler's Bat (Nyctalus leisleri), two Greater Mouse-eared Bats, two Lesser Mouse-eared Bats (Myotis blythii), six Geoffroy's Bats (Myotis emarginatus), nine Natterer's Bats (Myotis nattereri), 34 Bechstein's Bats (Myotis bechsteinii) and 23 Daubenton's Bats. The rest remained as ten unidentified vespertilionids (small Myotis) and four totally undeterminable bats (Table 1). About $35 \%$ of bats were young individuals, as shown by the incomplete ossification of long bones.

Table 1 - Summary of bats predated by Genets between 2013 and 2016 at the Igue of Crégols.

\begin{tabular}{|c|c|c|c|c|c|}
\hline Species & 2013 & 2014 & 2015 & 2016 & Total \\
\hline Eptesicus serotinus & & & 1 & & 1 \\
\hline Nyctalus leisleri & 1 & & & & 1 \\
\hline Myotis myotis & 2 & & & & 2 \\
\hline Myotis blythii & 2 & & & & 2 \\
\hline Myotis emarginatus & 6 & 4 & & & 10 \\
\hline Myotis nattereri & 9 & 5 & & 13 & 27 \\
\hline Myotis bechsteinii & 34 & & 2 & 31 & 67 \\
\hline Myotis daubentonii & 23 & & & 4 & 27 \\
\hline Myotis mystacinus & & 3 & & & 3 \\
\hline Myotis sp. & 10 & & & 1 & 11 \\
\hline Undeterminated Bat & 4 & 5 & 3 & 10 & 22 \\
\hline Bats total & 91 & 17 & 6 & 59 & 173 \\
\hline Mammals total & 497 & 113 & 219 & 143 & 972 \\
\hline Bats/mammals & $18.31 \%$ & $15.04 \%$ & $2.74 \%$ & $41.26 \%$ & $17.80 \%$ \\
\hline
\end{tabular}

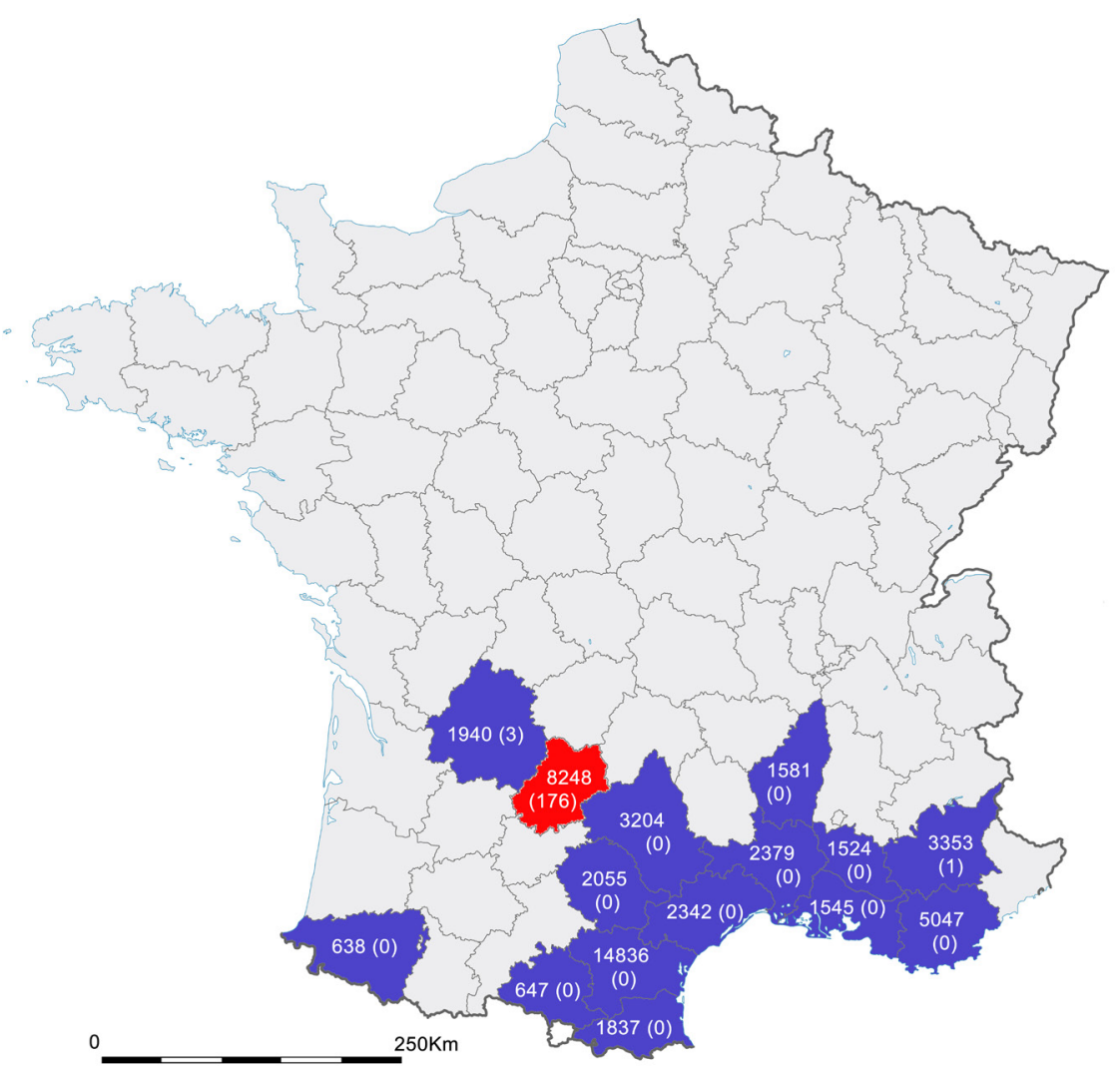

Fig. 3 - Number of bats predated by Common Genet in the studied departments in France (in parentheses), related to total identified items (top number). This map has been modified from Eric Gaba's map available (Wikimedia Commons). 
Table 2 - Summary of total items / prey / mammals and bats by department (samples with 500 preys).

\begin{tabular}{lcccl}
\cline { 2 - 4 } & Items total & Prey & Mammals & Bats \\
\hline Aude & 14,836 & 11,048 & 7,193 & 1 (undet.) \\
Lot (without Igue de Crégols) & 5,949 & 5,166 & 3,451 & 3 (1 Rhinolophus hipposideros + 2 undet.) \\
Igue de Crégols & $\mathbf{2 , 2 9 9}$ & $\mathbf{1 , 9 6 7}$ & $\mathbf{9 7 2}$ & $\mathbf{1 7 3}$ (9 species) \\
Var & 5,047 & 4,709 & 3,627 & 0 \\
Alpes de Haute-Provence & 3,353 & 2,228 & 1,074 & 1 Myotis myotis \\
Aveyron & 3,204 & 2,554 & 2,069 & 0 \\
Gard & 2,379 & 1,772 & 1,396 & 0 \\
Hérault & 2,342 & 1,841 & 1,281 & 0 \\
Tarn & 2,055 & 1,919 & 1,644 & 0 \\
Dordogne & 1,940 & 1,583 & 1,094 & 2 (1 Eptesicus serotinus + 1 undet.) \\
Ardèche & 1,581 & 908 & 517 & 0 \\
Bouches-du-Rhône & 1,545 & 1,178 & 649 & 0 \\
Vaucluse & 1,524 & 1,429 & 1,101 & 0 \\
Pyrénées-Orientales & 1,837 & 928 & 533 & 1 (undet.) \\
Ariège & 647 & 548 & 333 & 0 \\
Pyrénées-Atlantiques & 638 & 542 & 337 & 0 \\
\hline
\end{tabular}

In 2014, the scats' ages were also assessed for better understanding of the period of predation. At the same Crégols site, 20 new scats were collected in the January-June period. These revealed two Geoffroy's and three Natterer's bats (prior to April) out of 72 mammals ( 85 prey). And 19 more scats from summer and early autumn revealed twelve bats out of 27 mammals (136 prey) (Table 1): e.g. three Whiskered Bats (Myotis mystacinus), two Geoffroy's, two Natterer's and five unidentified; all taken as prey during September-October. This year the sampling site was far less visited, and all bats remains were in a very bad condition and crushed, while they were in a good condition in the 2013 sample (skulls almost complete and lower mandibles more or less intact).

In 2015, a further collection drawn from the Crégols site (77 scats for the entire year) provided only 6 bats from 219 mammals detected (277 prey) (Table 1): one Serotine, two Bechstein's Bats and three unidentified. That year, contrastingly, bat predation was globally very low $(2.74 \%)$, but three new species were added to the list of bats predated by the Viverrid in Lot.

In 2016, a final collection of 58 scats provided 59 bat individuals from a total of 143 mammals (469 prey) (Table 1), taken over about three months, representing a very high level of predation of more than $41 \%$ of mammals taken and eaten.

At present, there is no known predation at the sites in the vicinity of Grégols (Fig. 3): Combe Guilhaine (at 1.5 $\mathrm{km})$, St-Martin-Labouval $(2.7 \mathrm{~km})$, Tour de Faure $(3 \mathrm{~km})$, Roc Troucat $(7.8 \mathrm{~km})$ and Le Liauzu $(8 \mathrm{~km})$. Only in Marcilhac-onCélé (11 km far from) two bats were found: one unidentified (prior April) out of 105 scats (October 2013-June 2014) and one Lesser horseshoe Bat from 14 summer scats (2014). In other locations from the same department of Lot, where 49 other dropping places were surveyed from 35 different sites, we found only three bats (one Lesser Horseshoe Bat and two unidentified) from a total of 5,166 prey (5,944 items for 1,169 analyzed scats).

\section{DISCUSSION}

According to present knowledge captures of bats by the Common Genet are exceptional across its distributional range (Mas et al. 2015) including all southern France departments where our studies (Riols in prep) were carried out. Only one (unidentified little bat) has been found in Aude among 7,193 mammals (11,048 preys), none in Var/Vaucluse from 4,638 mammals (6,138 preys). And for the 11 other departments providing significant results (> 500 preys), four reports of bats being predated are known to us: one Greater mouse-eared Bat from 1,074 mammals (2,228 preys) in the Alps of Haute-Provence; one Serotine and one unidentified bat, from 1,094 mammals (1,583 preys) in Dordogne; and one unidentified bat from 533 mammals (928 preys) in the Pyrénées-Orientales.

The number of individuals involved in the case of Crégols is particularly noteworthy. However, the feeding activity upon bats clearly varies amongst different years: e.g. in 2014 about $15 \%$ of the number of mammals eaten by the Common Genet were bats, which was lower than the percentage (> 18\%) eaten in 2013 (Riols 2014). This same year, the poor condition of bats' remains, strongly crushed, would indicate the substitution of the genet - or one of the genets - that previously hunted here by another showing a greater masticatory capacity. The lower number of bats found in 2015 could possibly have been explained by weather factors, with a very rainy season.

This area of the Lot valley is particularly rich in bats: e.g., a castle $3.7 \mathrm{~km}$ from the igue shelters a colony of Greater, Lesser and Mediterranean horseshoe Bats and Geoffroy's Bats, and a mill $4 \mathrm{~km}$ away harbors in its roof a colony of Common Pipistrelle. However, most bats found in the scats probably would have been taken on the very site of the 
igue. According to their conservation condition, almost all 2013 scats would have been deposited between May and December. Furthermore, not a single bat was found among the 226 prey individuals identified in a scat batch collected on a nearby cliff (1.5 km away) in October 2009. If the richness of the surroundings was enough to explain this outstanding bat consumption, probably other genets would have exploited this resource elsewhere in similar proportions.

Considering the nine species of bats whose remains were identified in genet scats, three are usually treedwellers (Leisler's, Bechstein's and Daubenton's Bats) while others are cave-dwelling (Serotine, Greater and Lesser Mouse-eared Bats, Whiskered, Geoffroy's and Natterer's Bats) (Dietz et al. 2009). These species have different activity patterns, from the earlier Leisler's, which starts hunting by daylight, to the later Greater Mouse-eared Bat, which waits for pitch-dark (Arthur \& Lemaire 2009). Among the nine species taken by the Common Genet at the Crégols site, seven are Myotis, three of them (Natterer's, Bechstein's and Daubenton's) accounting for almost $70 \%$ of the consumption rate. Also, although at least 33 bats (19\% of the total) remain unidentified, they probably consisted mainly or even totally of small Myotis (see Table 2). Several different hypotheses that could possibly explain such predation rates are addressed below.

\section{A) Predation upon lethargic bats in their winter roosts.}

Such predation seems very unlikely for the 4 little Myotis which are found in cracks and holes, where they are often in dorso-ventral contact with the wall, thus, hardly accessible to the predator (Vaslin, pers. comm.).

\section{B) Predation upon bats going hunting and picked at exit on autumn roosting sites.}

We got a certain number (about 35\%) concern nonadult bats, thus theoretically less experienced after their emancipation (August-September). Such cases could support this hypothesis. Natterer's Bat is known as very vulnerable to domestic cat predation, and despite the fact that one cannot rule out that it would be equally vulnerable to the Common Genet, Bechstein's and Natterer's are probably regularly present throughout the summer (males) or prospecting in late summer (the young) at access level. If a genet found a suitable ambush position near a flyway, it could behave as a cat. Both species of bats remind of such predation when in flight: once in the cave, they would be inaccessible at the bottom of deep cracks where they hide during the daytime or else are active or up too high to be easily caught: a kind of ambush for bats (Arthur, pers. comm).

The complementary data gathered in autumn in 2014, 2015 and 2016 reinforced the following hypothesis: the genet takes advantage of the swarming period, autumnal or not, and capture at the cave exit from a suitable position. Large numbers of captures suggest at least some genets' assiduity in frequenting and exploiting the site and its resources.

The only biological possibility that would explain the number of all these species (with quite different ecologies) being in the same place and at the same time is the existence of a swarming site in the neighborhood: in the autumn, such sites in southern France can simultaneously, and in large numbers, accommodate up to ten or so species of bats. In addition, the bats' behaviour during these gatherings makes the likelihood of their being captured on account of their unceasing comings and goings within confined spaces greater (Vaslin, pers. comm). It is reminiscent of swarming periods when bats are very active near caves and very busy, even inattentive, which aligns well with Bechstein's and Daubenton's bat behaviors. Absence of anthropophilous species (Serotine, Pipistrelles) can be noted while the occurrence of Leisler's Bats here in this rocky surrounding is questionable: probably the genet has more regular periods when it goes hunting in nearby woodlands (Lemaire, pers. comm). The breeding frenzy at a swarming place is very real, many bats have only one idea: pairing. As they communicate very frequently (permanent social calls especially), they become a noisy congregation of less cautious individuals that create an easier catch for a genet, if a higher position allows it to strike at the point of entrance or exit (Bernard, pers. comm.). This autumn swarming phenomenon mainly concerns small Myotis, including two of the much-predated species (Natterer's and Daubenton's bats, accounting for $19 \%$ of the 140 identified bats) with the difference that the former swarms later (September to mid-October) than the second (August to beginning of September) (Arthur \& Lemaire 2009, Dietz et al. 2009). For several hours, from nightfall to midnight, bats' endless noisy comings and goings (social calls, songs), lack of caution and often flying in pairs (adult pairs or females with their young), can easily draw the predator and make predation much easier. On the other hand, the large numbers of Bechstein's (47.8\% of identified items) are reminiscent of another swarming form, in front of a summering colony or before a change of roosting site. Even for Natterer's Bat at another time of the annual cycle, the behavior at risk may be twilight swarming before going hunting.

\section{C) Genets feeding on bat carcasses that fall on the ground.}

Feeding on fallen carcasses through diffused mortality is possible, although less likely. This behavior is known for martens in a huge bat wintering site in Poland but in quite a much different context (Schofield 2012).

The principal hypothesis (B) regarding the Common Genet feeding on bats at the Grégol site during swarming period seems the more reliable so far. Lower capture numbers in 2014 could be partly explained by a more punctual swarming phenomenon. Factors influencing these bat behaviors - specifically those yet to be explained - could influence temporal variability such as the daily differences on swarming activity, meteorological, hormonal and social parameters or others. Genet(s) can recall the autumnal mass presence of bats but it appears less conceivable that they could anticipate the precise days of maximal activity. In fact, even predation fluctuation could conceivably be connected to a degree of hazard (Bernard, pers. comm), depending on the local circumstances. Very low predation in 2015 shows either considerably reduced swarming or a time shift between swarming and the genet's predatory presence. 


\section{CONCLUSION}

Compared to the quasi lack of bats in the many batches of genet scats analyzed in southern France, from which a good proportion came from sites where bats are fairly common, the regular occurrence of predation by one or several genets on bats visiting the Igue of Crégols seems related to very specific circumstances. Firstly, the existence of an important swarming place involving a number of bats, mainly various Myotis, at different autumnal times and with a large proportion of non-adult individuals (hypothesis B); and secondly, the outstanding configuration of the site, that is an igue and the original geological feature of Quercy's limestone plateau. The walls of this shallow hole, resulting from the roof of a cave collapsing, are very cracked. On the major part of the site, genets have easy access to every level of the cliff: ledges, shelves and bushes are within the reach of this rock predator. However, the overhanging part facing south, where much of the bats' guano concentrates, seems less accessible.

At one point in time, a genet, or several, had identified bat activity and taken the opportunity of exploiting this temporally available resource year after year and this looks like a true local specialization, cultural evolution grew out of a learned group behavior. The possible temporal variations of bat activity, depending on weather conditions, can at least partly explain changes in predation intensity (from 2.7 to $41.3 \%$ of predated mammals). It is highly probable that this phenomenon has existed for ages and only a random collection of genet scats, from this site, has allowed bringing it to light. Our observations from Lot highlight the Common Genet's predation potentialities on a bat population as much for numbers as specific diversity. In the same way, a survey of the bat population on the Crégols site needs to be engaged for a better understanding of this very local phenomenon. The only known example of other medium-sized generalist carnivores showing specialization for eating bats is the case of martens, both partially scavengers and active predators, at the Polish site of Nietoperek (Schofield 2012).

\section{ACKNOWLEDGEMENTS}

Our sincere thanks to Laurent Arthur, Matthieu Bernard, Michèle Lemaire, Claude Milhas, Philippe Tyssandier (the latter also enabled our contact with Maria Mas) and Matthieu Vaslin for their well-informed advice, to Patrick \& Liz Borredon for proofreading our text and to two anonymous reviewers. And special thanks to Jean-Jacques Chaut for his identifications, often in very arduous conditions.

\section{REFERENCES}

ARTHUR, L. \& LEMAIRE, M. (2009). Les Chauves-souris de France, Belgique, Luxembourg et Suisse. Biotope, Mèze (Collection Parthénope). Muséum National d'Histoire Naturelle, Paris. 544 p.

BEKKER, J.P. (1988). Watervleermuis, Myotis daubentoni, als prooi van Steenmarter, Martes foina, in ondergrondse mergelgroeven. Lutra, 31(1): 82-85.
BERTRAND, A. (1992). La prédation d'un Grand Murin Myotis myotis (Borkhausen, 1797) par le Blaireau Meles meles (Linnaeus, 1758). Le Rhinolophe, 9(1): 63-64.

BRITTON-MELLA, M.C. (1982). Les chauves-souris du BasLanguedoc: clés de détermination et leur application à la reconnaissance des restes osseux de chiroptères dans les pelotes de réjection de Rapaces. EPHE, Vertébrés. Montpellier, $41 \mathrm{pp}$.

DIETZ, C., DIETMAR, N. \& VON HELVERSON, O. (2009). L'Encyclopédie des Chauves-souris d'Europe et d'Afrique du Nord. Delachaux et Niestlé, Paris, France, 400 pp.

JEDRZEJEWSKA, B. \& JEDRZEJEWSKI, W. (1959). Predation in Vertebrate Communities. The Bialowieza Primeval Forest as a Case Study. Ecological Study 135. Springer Verlag Berlin-Heidelberg, Germany, 443 pp.

LESINSKI, G., KASPRZYK, K. \& GRYZ, J. (2012). Bats taken by the Tawny Owl in relation to its roosting site. Northwestern Journal of Zoology, 8(2): 247-251.

LIMA, S.L, \& O'KEEFE, J.M. (2013). Do predators influence the behaviour of bats? Biological Reviews, 88(3) : 626644. https://doi.org/10.1111/brv.12021

MAS, M., LOPEZ-BAUCELLS, A. \& ARRIZABALAGA, A. (2015). Predation on bats by genets Genetta genetta (Linnaeus, 1758): a review. Barbastella 8(1): 6-11. https://doi. org/10.14709/BarbJ.8.1.2015.03

MENU, H.\& POPELARD, J.B. (1987). Utilisation des caractères dentaires pour la détermination des Vespertilionidés de l'ouest européen. Le Rhinolophe, 4(1): 1-88.

NADAL, R. \& RIOLS, C. (2011). Bilan de 2 années de prospection de la Genette dans le sud du Lot. Lot Nature. Bulletin de liaison, 25(1): 12-21.

RIOLS, C. (2014). Prédation inhabituelle de chauves-souris par la Genette (Genetta genetta). L'Affût. Bulletin de liaison, 15(1): 29-34.

ROMANOWSKI, J. \& LESINSKI, G. (1991). A note on the diet of Stone marten in southeastern Romania. Acta Theriologica, 36 (1-2): 201-204.

ROULIN, A. \& CHRISTE, P. (2013). Geographic and temporal variation in the consumption of bats by European Barn Owl. Bird Study, 60(4) : 561-569. https://doi.org/10.108 $0 / 00063657.2013 .847051$

SCHOFIELD, H. (2012). Nietoperek, Poland - annual bat sensus and study of marten predation. Vincent Wildlife News 1: 5-7. 